\title{
El matrimonio de parejas del mismo sexo y la Corte Constitucional de Colombia*
}

\author{
Carlos Jesús Molina Ricaurte** \\ Yudy Andrea Carrillo Cruz***
}

\begin{abstract}
RESUMEN
En Colombia, las personas homosexuales forman parte de un grupo que ha sido históricamente marginado y discriminado, inclusive por el Derecho. La Corte Constitucional ha tenido un papel preponderante en el reconocimiento de derechos a personas homosexuales; desde una interpretación evolutiva, ha ido extendiendo su protección, primero al ejercicio de los derechos individuales sin discriminación hasta llegar a derechos como a conformar una familia y contraer matrimonio. Desde el 30 de junio de 2013, las parejas del mismo sexo quedaron facultadas por un fallo de la Corte Constitucional a acudir a notarios y jueces de la República para formalizar y solemnizar su unión mediante un vínculo contractual. Este artículo plantea como problema la competencia de la Corte para intervenir en temas que son de configuración exclusiva del Congreso. Los autores realizan una revisión documental de jurisprudencia de la Corte y de normas nacionales e internacionales para responder a este problema.
\end{abstract}

Corte Constitucional - derechos de los homosexuales - matrimonio de parejas del mismo sexo

\section{The marriage of same-sex couples and the Constitutional Court in Colombia}

\begin{abstract}
In Colombia, gay people are part of a group that has been historically marginalized and discriminated, including by the law. The Constitutional Court has played a leading role in the recognition of rights to homosexuals; from an evolutionary interpretation, it has been extending its protection, first, the exercise of individual rights without discrimination and later to rights to form a family and marriage. Since June 30, 2013, the same-sex couples were empowered by
\end{abstract}

* Artículo de investigación producto del grupo de investigación Abogados Solidarios UCC (COL0059754).

** Abogado, Magíster en Filosofía. Docente Investigador en la Universidad Santo Tomás, Colombia. Correo electrónico: carlosjesus80@gmail.com.

*** Abogada, Magíster en Derecho Administrativo. Docente Investigadora en la Universidad Cooperativa de Colombia. Correo electrónico: andreacarrillo123@hotmail.com.

Artículo recibido el 25.8.2016 y aceptado para su publicación en este número el 5.1.2018. 
a judgment of the Constitutional Court to appear before notaries and judges of the Republic to formalize and solemnize their union through a contractual link.

The problem raised in this article is about the jurisdiction of the Court to intervene in matters that are the exclusive configuration of Congress. The authors do a documentary review of jurisprudence of the Court and of national and international laws to respond to this problem.

Constitutional Court - marriage of same sex couples - rights of gay people

\section{INTRODUCCIÓN}

A partir del 30 de junio de 2013, las parejas del mismo sexo en Colombia quedaron facultadas por un fallo de la Corte Constitucional (sentencia C-577 de 2011) para acudir a notarios y jueces de la República para formalizar y solemnizar su unión, mediante un vínculo contractual. El reconocimiento del derecho de las parejas del mismo sexo en Colombia a contraer matrimonio mediante contrato civil ha significado la concreción de otros derechos, como son a conformar familias y a la libre disposición de la voluntad.

El matrimonio está regulado por el Código Civil, en su artículo 113, de igual forma está consagrado por la Constitución Política, en su artículo 42, en ambos se alude a la condición de la diferencia de sexo de los contrayentes bajo la expresión "un hombre y una mujer", por tanto, hacer una interpretación diferente configuraría una sustitución de la Constitución. Además, el texto superior confiere al legislativo amplitud para legislar acerca de "las formas de matrimonio, la edad y capacidad para contraerlo, los deberes y derechos de los cónyuges, su separación y la disolución del vínculo" ${ }^{1}$ y, en ese sentido, goza de un margen más amplio de configuración legislativa.

Sin embargo, al constatar que la protección y garantía de los derechos de las parejas del mismo sexo ha sido posible gracias a la intervención judicial, y no por intervención legislativa, no es claro si la Corte Constitucional se mantiene aún dentro de sus atribuciones constitucionales o, al contrario, se ha extralimitado en el ejercicio de sus funciones invadiendo un espacio reservado a la configuración legislativa para poder dar protección a un grupo social que ha sido históricamente marginado y discriminado, inclusive por el Derecho.

Es necesario decir que la Corte, para poder ampliar los derechos limitados a parejas heterosexuales a parejas del mismo sexo, tuvo que proceder por vía de control de constitucionalidad; no obstante, para autorizar y declarar la validez del matrimonio entre personas del mismo sexo tuvo que revisar sus líneas jurisprudenciales anteriores, sobre todo antes de 2007. A partir de la sentencia C-075 de 2007, la Corte empezó a plantear y desarrollar la tesis de déficit de protección de los derechos de las parejas del mismo sexo, irradiando su ratio dicidendi a la jurisprudencia posterior, permitiendo la

\footnotetext{
${ }^{1}$ Constitución Política de Colombia, Asamblea Nacional Constituyente de Colombia, 1991, artículo 42.
} 
ampliación del reconocimiento y protección de los derechos de las personas del mismo sexo. Efectivamente, este cambio jurisprudencial se ha basado en una interpretación evolutiva del ordenamiento jurídico, como lo indica la Corte en la sentencia C-577 de $2011^{2}$.

Para dar respuesta al problema planteado en este artículo se hizo una revisión documental de sentencias de la Corte Constitucional de Colombia con el fin de determinar los derechos fundamentales que han sido reconocidos a las personas homosexuales por vía jurisprudencial y su respectivo alcance. Se indagó también en las normas internacionales ratificadas por el Estado colombiano y que forman parte del bloque constitucional para encontrar fundamentos normativos en el derecho convencional, sobre todo en los derechos humanos. A su vez, intentó rastrearse en las normas nacionales las categorías sospechosas con base en la orientación sexual, así como las consecuencias de la aplicación de estas categorías sospechosas. Por último, se recurrió a textos jurisprudenciales y a opiniones de autores para determinar la procedencia de la aplicación del test de igualdad estricto en los casos sometidos a la Corte, así como los alcances y límites del principio de libertad de configuración legislativa que determinan la competencia de la Corte para intervenir en los casos de omisión legislativa relativa.

Las principales categorías identificadas fueron 1) derechos fundamentales de las personas homosexuales, 2) categorías sospechosas, 3) test de igualdad y 4) principio de libre configuración legislativa, que se definen y relacionan para poder dar respuesta al problema planteado.

Nuestra tesis es que el tribunal constitucional tiene competencia, sea por mandato directo de la Constitución o por medio de control de constitucionalidad, facultad de la que se encuentra investido, para intervenir en los casos de omisión relativa del órgano legislativo y poner fin a un déficit de protección jurídica manifiesto, en el caso particular, el déficit de protección de derechos de las personas homosexuales declarado por la Corte Constitucional. El objeto de este trabajo es dilucidar y alcanzar mayor claridad respecto del conflicto de competencias que se da entre órganos estatales, judicial y legislativo, en los casos de omisión legislativa relativa, concretamente, frente al déficit de protección de derechos de las personas homosexuales declarado.

Esta competencia que se atribuye a la Corte Constitucional para subsanar las omisiones legislativas tiene origen en la evolución de la forma de actuación de los poderes públicos, especialmente después de la Segunda Guerra Mundial. Históricamente los poderes más sobresalientes han sido el poder ejecutivo y el poder legislativo, su elección casi siempre ha sido democrática y, en ese sentido, han representado los intereses de las mayorías. No

2 "La interpretación evolutiva no se produce, entonces, de manera súbita e inconsulta, sino como el resultado de un proceso que progresivamente ha conducido a ajustar el sentido de las cláusulas constitucionales a las exigencias de la realidad o a las inevitables variaciones, proceso que ya había sido objeto de consideración en la Corte y cuya ocurrencia está prevista en la jurisprudencia constitucional al explicar el concepto de constitución viviente, que 'puede significar que en un momento dado, a la luz de los cambios económicos, sociales, políticos e incluso ideológicos y culturales de una comunidad, no resulte sostenible a la luz de la Constitución -que es expresión, precisamente, en sus contenidos normativos y valorativos de esas realidades'”. Sentencia C-577 de 2011, Corte Constitucional de Colombia, M. P. Gabriel Eduardo Mendoza Martelo. 
sucede lo mismo con la rama judicial que, en Colombia, se conforma por servidores que concursan por méritos para obtener los cargos, y respecto de la Corte Constitucional, su elección se realiza con quienes cumplen los requisitos constitucionales y legales para el cargo y son elegidos por el Senado de la República ${ }^{3}$, de modo que indirectamente las mayorías sí intervienen en la elección de los magistrados.

La historia confirma que las mayorías también pueden fallar en la toma de decisiones. Un hecho que demuestra la afirmación anterior es la Alemania nazi, donde se eligió un líder de forma democrática, y se justificaron un sinnúmero de atrocidades cometidas por el régimen bajo el argumento que hacía parte de la política de Estado. Lo anterior ha llevado a una progresiva pérdida de reputación del poder legislativo, y a replantear los mecanismos de toma de decisión por medio de las mayorías. Estos fenómenos han logrado que pueblos como Colombia respeten las decisiones del Tribunal Constitucional, al salvaguardar los derechos de todos los asociados, y subsanar las omisiones del legislador.

Después de la Segunda Guerra Mundial cambió el paradigma del juez como simple operario de la norma, a ser el rostro de la justicia que, de acuerdo con autores como Perelman (citado por Socorro Vásquez Posada), es complemento indispensable del legislador ${ }^{4}$.

La Corte Constitucional es el guardián de la Constitución Política, donde se consagran todos los derechos de la población. Su papel es fundamental para la protección efectiva de los derechos. Precisamente, el primer aspecto en analizar en el presente artículo son los derechos que, con el tiempo, se han ido reconociendo a las parejas del mismo sexo.

\section{LOS DERECHOS FUNDAMENTALES DE LAS PERSONAS HOMOSEXUALES}

Si bien todas las personas naturales tienen derechos fundamentales por el solo hecho de ser seres humanos, el ejercicio de los mismos se ha visto supeditado a los estándares socialmente reconocidos y aceptados por toda la colectividad, ignorando que hay muchas personas que pueden ser diferentes al statu quo, como sería el caso de las personas homosexuales, a quienes históricamente se les ha coartado el ejercicio pleno de sus derechos fundamentales y se les ha negado el libre desarrollo de la personalidad.

En este orden de ideas, los derechos fundamentales de las personas homosexuales se han declarado, sobre todo, por vía judicial. Esto quiere decir que la Corte Constitucional, máximo órgano de la jurisdicción constitucional en Colombia, ha tenido un papel preponderante en el reconocimiento de estos derechos. Es menester, para determinar el elenco de derechos fundamentales que asisten a las personas homosexuales, hacer

\footnotetext{
${ }^{3}$ Constitución Política de Colombia, Asamblea Nacional Constituyente de Colombia, 1991, artículo 173.

${ }^{4}$ Vásquez, S., La Argumentación Judicial, Librería Jurídica Sánchez Ltda., Medellín, 2003, p. 38. "Hoy, ciertamente, los jueces tienen una gran responsabilidad en la vida del derecho desconocida en los ordenamientos del Estado de derecho legislativo. Pero los jueces no son los señores del derecho en el mismo sentido en que lo era el legislador en el pasado siglo. Son más exactamente los garantes de la complejidad estructural del derecho en el Estado constitucional”. Zagrebelsky, G., El derecho dúctil. Ley, derechos, justicia, Editorial Trotta, Madrid, 2011, p. 153.
} 
una revisión de la jurisprudencia de dicho tribunal, y para ello es necesario conocer la evolución jurisprudencial en la que ha tenido efectividad el reconocimiento de estos derechos. Como lo mencionan Quinche y Peña, los fallos proferidos entre 1992 y 2007 se caracterizan por establecer la defensa de las personas homosexuales tan solo en el plano individual, con preferencia en el derecho de acceso y permanencia en el trabajo, en la educación y el derecho a la imagen ${ }^{5}$. Sin embargo, un fallo que pertenece al período mencionado, la sentencia T-539 de $1994^{6}$, establece una posición que ha servido para que la Corte Constitucional, en reiteradas ocasiones (e.g. sentencia C-481 de 1998) ${ }^{7}$, se haya pronunciado acerca de los derechos de las personas homosexuales.

De acuerdo con la declaración y mandato de la Corte, no hay razón para no reconocer a las personas homosexuales como titulares de derechos fundamentales, menos aún para dispensarles un trato diferente en razón de su orientación sexual.

Sin duda, un avance significativo en la declaración de derechos de las personas homosexuales fue la sentencia C-075 de 2007, mediante esta, la Corte hizo expreso el reconocimiento de la existencia de las parejas del mismo sexo y extendió los beneficios y las medidas de protección del régimen patrimonial reconocido a las uniones de hecho de parejas heterosexuales a las uniones de parejas conformadas por homosexuales. "[Las parejas homosexuales] plantean, en el ámbito patrimonial, requerimientos de protección en buena medida asimilables a aquellos que se predican de la pareja heterosexual"8.

En esa oportunidad, la Corte Constitucional identificaba, por primera vez, un "déficit a la luz del ordenamiento constitucional" que excluía a las parejas homosexuales del régimen patrimonial reconocido a las parejas heterosexuales y establecía un tratamiento diferenciado respecto de estas últimas?.

En un nuevo pronunciamiento, la sentencia C-336 de 2008, la Corte decidió a favor de las parejas del mismo sexo extendiendo los derechos y prerrogativas de las uniones

\footnotetext{
${ }^{5}$ Quinche, M. \& Peña, R, El derecho judicial de la población LGTBI y de la familia diversa, Legis Editores, Universidad del Rosario, Bogotá, 2013, pp. 31-32

6 "Los homosexuales son titulares de todos los derechos fundamentales de la persona humana, y no hay título jurídico para excluirlos de las actitudes de respeto, justicia y solidaridad. Se recuerda que en Colombia ninguna persona puede ser marginada por razones de sexo (Art. 13 C.P.) y que el derecho a la intimidad esté protegido y tutelado por nuestro Estado social de derecho (Art. 15 C.P.)". Sentencia T-539 de 1994, Corte Constitucional de Colombia, M. P. Vladimiro Naranjo Mesa.

${ }^{7}$ Cfr. Sentencia C-481 de 1998, Corte Constitucional de Colombia, M.P. Carlos Gaviria Díaz.

${ }^{8}$ Sentencia C-075 de 2007, Corte Constitucional de Colombia, M.P. Rodrigo Escobar Gil.

9 "Las mismas consideraciones que permiten establecer que en relación con la situación patrimonial de las parejas homosexuales existe un déficit de protección a la luz del ordenamiento constitucional, llevan a la conclusión de que el régimen de la Ley 54 de 1990, tal como fue modificado por la Ley 979 de 2005 , en la medida en que se aplica exclusivamente a las parejas heterosexuales y excluye de su ámbito a las parejas homosexuales, resulta discriminatorio. Así, no obstante las diferencias objetivas que existen entre los dos tipos de pareja, y las específicas consideraciones que llevaron al legislador del año 1990 a establecer este régimen de protección, fundadas en la necesidad de proteger a la mujer y a la familia, no es menos cierto que hoy por hoy puede advertirse que la parejas homosexuales presentan requerimientos análogos de protección y que no existen razones objetivas que justifiquen un tratamiento diferenciado”. Sentencia C-075 de 2007, Corte Constitucional de Colombia, M.P. Rodrigo Escobar Gil.
} 
de hecho heterosexuales a las parejas homosexuales, no solo en el ámbito patrimonial sino también a otros ámbitos, "por encontrarse en una situación asimilable" y por no existir razones que justificaran dar un trato diferente a estas ${ }^{10}$.

En otro fallo, la sentencia C-029 de 2009, la Corte hizo alusión a la existencia y reconocimiento jurídico de las parejas de personas del mismo sexo ${ }^{11}$.

A pesar de que la Corte Constitucional reconociera la existencia de parejas del mismo sexo y predicara la igualdad de derechos respecto de las parejas de distinto sexo, en la práctica, aún persistía un déficit de protección jurídica a estas parejas, por cuanto no podían acceder al matrimonio.

En la sentencia C-577 de 2011 habría de decidir respecto de la exequibilidad ${ }^{12}$ del artículo 113 del Código Civil, del tenor: "El matrimonio es un contrato solemne por el cual un hombre y una mujer se unen con el fin de vivir juntos, de procrear y de auxiliarse mutuamente". Para el caso de la expresión "un hombre y una mujer", la Corte la declaró exequible; mientras que frente a la expresión "de procrear", se declaró inhibida para pronunciarse de fondo. De conformidad con los cargos presentados en la demanda, el artículo 113, al reglamentar el matrimonio, lo hacía con referencia a las parejas de personas de distinto sexo, pero no respecto de las parejas de personas del mismo sexo, por tanto excluía a estas, y se presentaba una omisión legislativa relativa que creaba una situación de desigualdad entre parejas conformadas por personas de distinto sexo y las parejas de personas del mismo sexo. Sin embargo, la fórmula del artículo 113 estaba en consonancia con el artículo 42 de la Constitución Política, lo que dificultaba a la Corte hacer una nueva interpretación del artículo 42 superior sin que esto implicara necesariamente una sustitución de la Constitución. El artículo 42 de la Constitución reza: "La familia es el núcleo fundamental de la sociedad. Se constituye por vínculos naturales o jurídicos, por la decisión libre de un hombre y una mujer de contraer matrimonio o

10 "La protección otorgada a los compañeros y compañeras permanentes de las parejas heterosexuales, debe ser ampliada a los compañeros y compañeras permanentes de las parejas homosexuales, por cuanto no existe un fundamento razonable y objetivo suficiente para explicar el trato desigual al que vienen siendo sometidas las personas que en ejercicio de sus derechos al libre desarrollo de la personalidad y a la libertad de opción sexual, han decidido conformar una pareja con una persona de su mismo género". Sentencia C-336 de 2008, Corte Constitucional de Colombia, M. P. Clara Inés Vargas Hernández.

11 "La pareja, como proyecto de vida en común, que tiene vocación de permanencia e implica asistencia recíproca y solidaridad entre sus integrantes, goza de protección constitucional, independientemente de si se trata de parejas heterosexuales o parejas homosexuales, y que, en ese contexto, la diferencia de trato para parejas que se encuentren en situaciones asimilables puede plantear problemas de igualdad y que, del mismo modo, la ausencia de previsión legal para las parejas del mismo sexo en relación con ventajas o beneficios que resultan aplicables a las parejas heterosexuales, puede dar lugar, a un déficit de protección contrario la Constitución, en la medida en que desconoce un imperativo superior conforme al cual, en determinadas circunstancias, el ordenamiento jurídico debe contemplar un mínimo de protección para ciertos sujetos, mínimo sin el cual pueden verse comprometidos principios y derechos superiores, como la dignidad de la persona, el libre desarrollo de la personalidad o la solidaridad”. Sentencia C-029 de 2009, Corte Constitucional de Colombia, M. P. Rodrigo Escobar Gil.

12 "Clase de sentencia emitida por la Corte Constitucional en la que se manifiesta que una ley es acorde a la Constitución Política”. Tomado de http://www.senado.gov.co/glosario/Glosario-1/E/Exequibilidad-15/, consultado 15 de noviembre de 2016. 
por la voluntad responsable de conformarla”. En este artículo, la Constitución consagra la institución familiar como núcleo fundamental de la sociedad, que se encuentra bajo especial protección de la sociedad y el Estado, constituida por vínculos naturales o jurídicos, cuyo origen está en la decisión de un hombre y una mujer de contraer matrimonio o por la voluntad responsable de conformarla.

En las sentencias previas a la C-577 la protección a las pareja [sic] del mismo sexo siempre estuvo circunscrita a la figura de la unión marital de hecho, en cuya presencia solo lograban disfrutar de derechos y deberes con marcado acento patrimonial. Sin embargo, para la Corte este régimen jurídico debía ampliarse para hacerlo comprender también otras dimensiones más personales de la vida en pareja ${ }^{13}$.

En torno a la discusión respecto del matrimonio de parejas del mismo sexo, aún estaba por resolver la cuestión de si debía reconocérseles a las parejas del mismo sexo el estatus como familia. La interpretación literal del artículo 42 superior sugiere que la celebración del matrimonio está reservada casi exclusivamente a las parejas heterosexuales, excluyendo de plano a las parejas del mismo sexo de contraer matrimonio; no obstante, tampoco excluye expresamente a las parejas de mismo sexo de la posibilidad de conformar familias ${ }^{14}$.

El análisis realizado por la Corte llevó a determinar que las parejas del mismo sexo compartían un elemento común con las parejas de distinto sexo, que les permitía configurarse como familia ${ }^{15}$. Determinó, entonces, la Corte que:

La presencia en las uniones homosexuales estables del elemento que le confiere identidad a la familia más allá de su diversidad y de las variaciones que tenga su realidad, su concepto y su consecuente comprensión jurídica, las configura como familia y avala la sustitución de la interpretación que ha predominado en la Corte ${ }^{16}$.

\footnotetext{
13 Páez, M., "La sentencia C-577 de 2011 y el matrimonio igualitario en Colombia", en Revista Derecho del Estado Universidad Externado de Colombia, No 31, julio 2013, p. 236.

14 " [La Corte] ha hecho alusión a diversas clases de familia distintas de la heterosexual y monogámica y como resultado de ese análisis procede destacar la situación paradójica que se presenta cuando el alcance de un texto, como el contenido en el primer inciso del artículo 42 superior, se fija con base en una interpretación literal y la materia regulada es esencialmente variable, propensa a ser influida por circunstancias sociales cambiantes que se traducen en la rápida evolución de las percepciones, cuya incidencia se proyecta no solo en los grandes movimientos de las concepciones colectivas, sino también en la vida cotidiana de personas concretas”. Sentencia C-577 de 2011, Corte Constitucional de Colombia, M. P. Gabriel Eduardo Mendoza Martelo.

15 "La Corte considera que no existen razones jurídicamente atendibles para sostener que entre los miembros de la pareja homosexual no cabe predicar el afecto, el respeto y la solidaridad que inspiran su proyecto de vida en común, con vocación de permanencia, o que esas condiciones personales solo merecen protección cuando se profesan entre heterosexuales, mas no cuando se trata de parejas del mismo sexo". Sentencia C-577 de 2011, Corte Constitucional de Colombia, M. P. Gabriel Eduardo Mendoza Martelo.

${ }^{16}$ Sentencia C-577 de 2011, Corte Constitucional de Colombia, M. P. Gabriel Eduardo Mendoza Martelo.
} 
Esto la llevó a reformular la definición de familia, bajo un análisis sistemático del ordenamiento jurídico, que situó la institución de la familia en el contexto de pluralismo y diversidad ${ }^{17}$. Así, la Corte dio cabida al reconocimiento de familias diversas a la formada por parejas heterosexuales: "La heterosexualidad no es, entonces, característica predicable de todo tipo de familia y tampoco lo es la consanguinidad, como lo demuestra la familia de crianza, de manera que otro ha de ser el denominador común de la institución familiar en sus diversas manifestaciones" ${ }^{18}$. La Corte Constitucional puso en esta sentencia énfasis en el libre desarrollo de la personalidad y en la expresión libre de la voluntad libre de conformar una familia ${ }^{19}$.

Respecto del matrimonio, ha dicho la Corte: "en todo caso constituye en familia a la pareja que, con esa finalidad, manifiesta libremente su consentimiento" 20 . Posteriormente, en la sentencia SU-214 de 2016 afirmó que "el fin del matrimonio es en esencia la consolidación de lazos de voluntad o convivencia, que permiten conformar una familia" 21 .

La sentencia C-577 de 2011 fue emblemática y marcó un giro en la jurisprudencia de la Corte Constitucional, por cuanto hizo un reconocimiento explícito de las parejas conformadas por personas del mismo sexo como un tipo de familia amparado por el ordenamiento jurídico colombiano, pero también porque identificó un déficit de protección jurídica que afectaba a estas parejas. En la misma providencia, la Corte hizo un exhorto al Congreso de la República para que, en el plazo perentorio de 20 de junio de 2013 legislara de manera sistemática y organizada con la finalidad de eliminar el déficit de protección que afectaba a las parejas conformadas por personas del mismo sexo.

Este fallo también es conocido porque sus efectos fueron modulados, de suerte que, de manera diferida, facultaba a las parejas de personas del mismo sexo a acudir a notarios o jueces de la República para formalizar y solemnizar sus uniones mediante un vínculo contractual, en caso de que el Congreso no legislara en el término establecido.

Muchos interpretaron el fallo como la autorización de la Corte Constitucional a celebrar convenios especiales para dar origen a las relaciones familiares de las parejas de personas del mismo sexo. Sin embargo, si se tiene en cuenta que figuras innominadas y atípicas, como los pactos de unión civil o los acuerdos de mera convivencia, solo

17 'La Corte ha definido la familia 'en un sentido amplio', como 'aquella comunidad de personas emparentadas entre sí por vínculos naturales o jurídicos, que funda su existencia en el amor, el respeto y la solidaridad, y que se caracteriza por la unidad de vida o de destino que liga íntimamente a sus integrantes más próximos'”. Sentencia C-577 de 2011, Corte Constitucional de Colombia, M. P. Gabriel Eduardo Mendoza Martelo, citando la Sentencia C-271-2003, Corte Constitucional de Colombia, M. P. Rodrigo Escobar Gil.

${ }^{18}$ Sentencia C-577 de 2011, Corte Constitucional de Colombia, M. P. Gabriel Eduardo Mendoza Martelo.

19 “ $[\mathrm{L}] \mathrm{a}$ sola pareja que libremente manifiesta su consentimiento o se une con vocación de permanencia es ya una familia, así en el matrimonio como en la unión marital de hecho que, tradicionalmente y para distintos efectos, ha sido aceptada como familia aún sin descendientes, luego la situación no puede ser distinta en el caso de las personas homosexuales que conforman una unión estable". Sentencia C-577 de 2011, Corte Constitucional de Colombia, M. P. Gabriel Eduardo Mendoza Martelo.

${ }^{20}$ Sentencia C-577 de 2011, Corte Constitucional de Colombia, M. P. Gabriel Eduardo Mendoza Martelo.

${ }^{21}$ Sentencia SU-214 de 2016, Corte Constitucional de Colombia, M.P. Alberto Rojas Ríos. 
perpetuarían el déficit de protección identificado por la jurisprudencia constitucional, desde un punto de vista formal y material ${ }^{22}$, no tendrían, por tanto, una finalidad constitucional.

No podemos negar que si la voluntad inicial de la Corte Constitucional, al proferir el fallo, era proteger efectivamente a las familias de parejas del mismo sexo, esto implicaba cobijarlas con el régimen legal vigente, dispuesto en la Constitución, el Código Civil y las demás normas concordantes que disponen de un contrato civil de orden público como es el matrimonio ${ }^{23}$, de modo que no sería razonable la hipótesis de creación de acuerdos a conveniencia de las partes, negándoles con esto la seguridad jurídica y el marco de protección que sí puede conferir el matrimonio, y así quedó confirmado en la sentencia SU-214 de 2016, en la que se dijo explícitamente:

La Corte considera que interpretar que las parejas del mismo sexo deben realizar un contrato solemne, que no configura un matrimonio civil conduce, entre otros, a los siguientes resultados inadmisibles: (i) no constitución formalmente de una familia; (ii) no surgimiento de los deberes de fidelidad y mutuo socorro; (iii) los contratantes no modifican su estado civil; (iv) ausencia de una sociedad conyugal; (v) los contratantes no ingresan en el respectivo orden sucesoral; (vi) imposibilidad de suscripción de capitulaciones; (vii) falta de claridad sobre las causales de terminación del vínculo entre los contratantes; (viii) de llegar a establecer su residencia en otros países, las respectivas autoridades no les brindarían a la unión solemne, la protección legal que tienen los cónyuges, ya que éstas no les reconocen los efectos que tienen en nuestro sistema jurídico; y (ix) en materia tributaria no se podrían invocar ciertos beneficios por tener cónyuge o compañero permanente. En conclusión, ningún contrato solemne innominado o atípico, celebrado entre parejas del mismo sexo, podría llegar a producir los mismos efectos personales y patrimoniales que un matrimonio civil. De allí que los contratos civiles innominados, o que buscan solemnizar y formalizar las uniones entre parejas del mismo sexo, diferentes al matrimonio civil, no suplen el déficit de protección identificado en la Sentencia C-577 de $2011^{24}$.

En esta decisión trascendental, la Corte Constitucional, tras varios años de haber proferido la sentencia C-577 de 2011 en la que hizo explícito el reconocimiento a las parejas conformadas por personas del mismo sexo como un tipo de familia e identificaba el déficit de protección jurídica en su contra, resolvió varios expedientes acumulados de tutela y amparó el derecho de las personas homosexuales a contraer matrimonio civil

${ }^{22}$ Cfr. Páez, M., "La sentencia C-577 de 2011 y el matrimonio igualitario en Colombia", en Revista Derecho del Estado Universidad Externado de Colombia, No 31, julio 2013, p. 250.

${ }^{23}$ Cfr. Páez, M., "La sentencia C-577 de 2011 y el matrimonio igualitario en Colombia", en Revista Derecho del Estado Universidad Externado de Colombia, No 31, julio 2013, p. 248.

${ }^{24}$ Sentencia SU-214 de 2016, Corte Constitucional de Colombia, M.P. Alberto Rojas Ríos. 
y, además, resolvió extender el fallo con efecto inter pares a pares o semejantes ${ }^{25}$. Ahora bien, en la parte resolutiva de la sentencia de unificación entendió tácitamente el derecho de las personas homosexuales a contraer matrimonio como un derecho fundamental.

Lo cierto es que el alcance real de la sentencia SU-214 de 2016 no se podría dimensionar si no es con relación a la sentencia C-577-2011, pues esta última fue la que estableció las bases de la familia y el matrimonio como derechos fundamentales dentro del ordenamiento constitucional, situándolos como una manifestación del libre desarrollo de la personalidad ${ }^{26}$.

Ya puede figurarse por qué razón la Corte en la sentencia SU-214 de 2016, sin más, decidió amparar el derecho de contraer matrimonio civil, pues en un pronunciamiento anterior ya se había referido a este derecho otorgándole estatuto superior, basado en normas internacionales que conforman el bloque constitucional en Colombia ${ }^{27}$.

\section{Categorías sospechosas}

La Constitución no solo garantiza los derechos a las personas homosexuales, también prohíbe la discriminación por razón de sexo (art. 13) ${ }^{28}$. La discriminación a las personas homosexuales parte muchas veces de la utilización de categorías que justifican un trato diferente o discriminatorio a estas personas, en razón del sexo u orientación sexual. En la Constitución se enuncian motivos o criterios, aunque no en forma taxativa, que aluden a aquellas categorías que se consideran sospechosas, pues su uso ha estado históricamente asociado a prácticas que tienden a subvalorar y a colocar en situaciones de desventaja a ciertas personas o grupos, verbigracia mujeres, negros, homosexuales, indígenas, entre otros ${ }^{29}$.

Históricamente se han afianzado prejuicios en contra de los homosexuales, solamente porque se apartan de la opción sexual de la población mayoritaria. Estos prejuicios han impedido ver a los homosexuales como sujetos de derecho, postergando sus necesidades y demandas de igualdad de manera indefinida respecto del resto de la población. La situación tiende a agravar cuando se constata la existencia de mecanismos o barreras,

${ }^{25}$ Cfr. Sentencia SU-214 de 2016, Corte Constitucional de Colombia, M.P. Alberto Rojas Ríos.

26 "Es de interés puntualizar que, tanto la familia como el matrimonio, son derechos de carácter fundamental. Tratándose de la familia, la Corte ha precisado que es 'una manifestación del libre desarrollo de la personalidad y, en concreto, de la libre expresión de afectos y emociones', ya que 'su origen se encuentra en el derecho de la persona de elegir libremente entre las distintas opciones y proyectos de vida, que según sus propios anhelos, valores, expectativas y esperanzas, puedan construir y desarrollar durante su existencia". Sentencia C-577 de 2011, Corte Constitucional de Colombia, M. P. Gabriel Eduardo Mendoza Martelo.

${ }^{27}$ Convención Americana sobre Derechos Humanos "Pacto de San José de Costa Rica”, artículo 24; Pacto Internacional de Derechos Civiles y Políticos, artículo 26, y los Principios de Yogyakarta que, aunque no sean parte del bloque constitucional, contienen los parámetros internacionales de legislación acerca de derechos humanos en relación con la orientación sexual y la identidad de género.

${ }^{28}$ Cfr. Sentencia C-481 de 1998, Corte Constitucional de Colombia, M.P. Carlos Gaviria Díaz.

${ }^{29}$ Cfr. Sentencia C-371 de 2000, Corte Constitucional de Colombia, M.P. Carlos Gaviria Díaz. 
a veces de tipo legal, que impiden a las personas homosexuales acceder a sus derechos, lo que denota usualmente una voluntad de segregar y estigmatizar a estas poblaciones minoritarias, por lo que la diferencia de trato por razón de la orientación sexual resulta sospechosamente discriminatoria ${ }^{30}$.

La doctrina constitucional ha señalado que: "el homosexualismo, en sí mismo, representa una manera de ser o una opción individual e íntima no sancionable" ${ }^{31}$. Sea que la homosexualidad se considere bien como una forma de ser o como una opción individual, resulta sospechoso de trato discriminatorio, a la luz de la Constitución, dispensar un trato diferente a las personas homosexuales solo por el hecho de ser homosexuales. Al respecto, ha dicho la Corte:

En nuestro ordenamiento constitucional, la orientación homosexual, incluso si asumimos que esta es escogida libremente y no determinada biológicamente, no puede constituir un criterio para que la ley restrinja el acceso de la persona a un determinado bien o le imponga una carga, por cuanto las autoridades estarían no solo afectando su libre desarrollo de la personalidad (CP art. 16) sino que además desconocerían el pluralismo que la Carta ordena proteger $\left(\mathrm{CP}\right.$ art. $\left.7^{\circ}\right)$. En efecto, y tal y como esta Corte ya lo ha señalado con claridad, algunas manifestaciones de diversidad se encuentran amparadas constitucionalmente por el principio del pluralismo, por lo cual son "insuprimibles por la voluntad democrática”, y entre ellas se encuentra sin lugar a dudas la opción por una preferencia sexual, que al ser una decisión soberana del individuo, "no concierne al Estado, que ha de permanecer neutral, a no ser que la conducta de los sujetos objetivamente produzca daño social"32.

En general, el derecho constitucional contemporáneo considera como criterios sospechosos de clasificación aquellas categorías que:

(i) Se fundan en rasgos permanentes de las personas, de las cuales estas no pueden prescindir por voluntad propia a riesgo de perder su identidad; (ii) esas características han estado sometidas, históricamente, a patrones de valoración cultural que tienden a menospreciarlas; y, (iii) no constituyen, per se, criterios con base en los cuales sea posible efectuar una distribución o reparto racionales y equitativos de bienes, derechos o cargas sociales ${ }^{33}$.

Para la Corte la idea misma de nociones sospechosas, o potencialmente discriminatorias, y su uso por las autoridades se encuentra en principio prohibida (CP art. 13). Las autoridades deben, en principio, evitar emplear esas clasificaciones. Por esta razón,

\footnotetext{
${ }^{30}$ Cfr. Sentencia C-481 de 1998, Corte Constitucional de Colombia, M.P. Carlos Gaviria Díaz.

31 Sentencia T-097 de 1994, Corte Constitucional de Colombia, M.P. Eduardo Cifuentes Muñoz.

32 Sentencia C-481 de 1998, Corte Constitucional de Colombia, M.P. Carlos Gaviria Díaz.

33 Sentencia C-481 de 1998, Corte Constitucional de Colombia, M.P. Carlos Gaviria Díaz.
} 
si una diferencia de trato se funda en una categoría potencialmente discriminatoria, tienen que concurrir claras razones que expliquen su empleo ${ }^{34}$. No solo está proscrito el empleo de nociones sospechosas, o potencialmente discriminatorias, el trato diferenciado sustentado en la diferente orientación sexual rara vez puede decirse que cumple algún propósito constitucionalmente relevante ${ }^{35}$. Existen pocas razones que justifiquen un trato diferente a las personas homosexuales basado en su orientación sexual y, en el caso que haya, estas deben demostrarse.

La Corte precisa que "la finalidad de erigir el deber de fundamentar la constitucionalidad del trato discriminatorio, es resultado de la necesidad de evitar que, de manera infundada, se restrinja el acceso a una o a un grupo de personas al ejercicio efectivo de sus derechos y libertades sin que para ello medien motivos razonables y admisibles" 36 .

El trato diferenciado, en principio, no está prohibido por la Constitución ${ }^{37}$. Se habla, por eso, de una discriminación negativa y una discriminación positiva ${ }^{38}$. El trato diferenciado a personas homosexuales, basado en su orientación sexual, constituye una discriminación negativa, que para el ordenamiento jurídico colombiano, bajo ninguna circunstancia, resulta aceptable.

La Corte ha establecido que el trato diferenciado basado en la orientación sexual de las personas constituye una categoría sospechosa ${ }^{39}$. Sin embargo, es importante aclarar al respecto que no siempre la Corte reconoció la orientación sexual como una categoría sospechosa. En un primer momento utilizó la categoría sospechosa de sexo como criterio para examinar el trato diferenciado a personas homosexuales ${ }^{40}$. Fue después, mediante la sentencia C-481 de 1998, que la Corte abrió el camino para considerar la orientación sexual como categoría sospechosa de trato diferenciado a personas homosexuales, al establecer que toda diferencia de trato fundada en la diversa orientación sexual era equivalente a una posible discriminación por razón de sexo. Finalmente, en la sentencia T-301 de 2004, la Corte Constitucional hizo expresa referencia a la orientación sexual como criterio rector de trato diferenciado, y la manera cómo debía valorarse el trato diferenciado cuando estuviera presente el criterio sospechoso de la orientación sexual:

${ }^{34}$ Cfr. Sentencia C-112 de 2000, Corte Constitucional de Colombia, M.P. Alejandro Martínez Caballero.

35 Cfr. Sentencia C-481 de 1998, Corte Constitucional de Colombia, M.P. Carlos Gaviria Díaz.

36 Sentencia T-301 de 2004, Corte Constitucional de Colombia, M.P. Eduardo Montealegre Lynett.

37 “Así, la Corte ha señalado que para determinar si una diferencia de trato resulta discriminatoria, es preciso establecer, en primer lugar, si los supuestos de hecho son asimilables, en segundo lugar, debe indagarse sobre la finalidad del tratamiento diferenciado; a continuación debe determinarse si esa finalidad es razonable y, por consiguiente, constitucionalmente admisible; a reglón seguido debe indagarse sobre la adecuación del medio a los fines perseguidos, para, finalmente, superados los anteriores pasos, establecer si se satisface el criterio de la proporcionalidad”. Sentencia C-029 de 2009, Corte Constitucional de Colombia, M. P. Rodrigo Escobar Gil.

${ }^{38} \mathrm{La}$ discriminación positiva se refiere a las "medidas positivas dirigidas a corregir las desigualdades de facto, a compensar la relegación sufrida y a promover la igualdad real y efectiva” de individuos o grupos de individuos en situación de desventaja social, jurídica, educativa, laboral y política. Cfr. Sentencia C-371 de 2000, Corte Constitucional de Colombia, M.P. Carlos Gaviria Díaz.

${ }^{39}$ Cfr. Sentencia T-248 de 2012, Corte Constitucional de Colombia, M. P. Jorge Pretelt Chaljub.

${ }^{40}$ Cfr. Sentencia T-539 de 1994, Corte Constitucional de Colombia, M. P. Vladimiro Naranjo Mesa. 
"En estos eventos [en que se utiliza la condición homosexual como criterio sospechoso de discriminación] debe aplicarse un test estricto de igualdad, por cuanto difícilmente puede sustentarse un fin constitucionalmente admisible en punto de la restricción de la autodeterminación sexual" ${ }^{41}$.

Respecto de los actos de discriminación basados en la categoría sospechosa de la orientación sexual, las normas (inciso 2, art. 167, Código General del Proceso) establecen una presunción de inconstitucionalidad que favorece al accionante víctima de discriminación con la carga dinámica de la prueba, pasando del extremo accionante al extremo accionado, de suerte que la presunción de discriminación tenga que ser desvirtuada por quien ejecuta el presunto acto discriminatorio, y ya no probada por quien lo padezca ${ }^{42}$.

La discriminación por razones de la orientación sexual implica una infracción a las normas penales, lo que conlleva una garantía efectiva de los preceptos constitucionales. Por eso, en el 2011 el Gobierno Nacional sancionó la Ley 1482 que modificó el Código Penal colombiano, y agregó, entre otros, los artículos $134 \mathrm{~A}^{43}$ y $134 \mathrm{~B}^{44}$.

\section{Test DE IGUALDAD}

De acuerdo con Carlos Bernal Pulido, la indeterminación del principio de igualdad en el texto constitucional implica la interpretación de la Corte Constitucional para determinar el contenido del artículo 13, siempre que deba enjuiciar la constitucionalidad de las leyes o de los actos administrativos y de particulares ${ }^{45}$.

La Corte Constitucional ha establecido y aplicado diversos criterios para determinar el contenido del principio de igualdad frente a las leyes que son demandadas por inconstitucionalidad, o bien, frente a los actos administrativos o de los particulares, cuando se solicita el amparo constitucional de los derechos fundamentales. Estos criterios reciben el nombre de test y son tres. El primero de estos es de tradición europea, sigue un análisis de proporcionalidad, y busca establecer: a) la existencia de un objetivo perseguido por medio del trato diferenciado, b) la validez de ese objetivo a la luz de la Constitución y c) la razonabilidad del trato diferenciado, es decir, la relación de

${ }^{41}$ Sentencia T-301 de 2004, Corte Constitucional de Colombia, M. P. Eduardo Montealegre Lynett.

${ }^{42}$ La Corte se refirió a esta inversión de la carga de la prueba en estos términos: "Los actos discriminatorios suelen ser de difícil prueba. De ahí que sea apropiado que la carga de probar la inexistencia de discriminación recaiga en cabeza de la autoridad que expide o aplica una disposición jurídica, no así en quien alega la violación de su derecho a la igualdad, especialmente cuando la clasificación que se hace de una persona es sospechosa por tener relación con los elementos expresamente señalados como discriminatorios a la luz del derecho constitucional”. Sentencia T-098 de 1994, Corte Constitucional de Colombia, M. P. Eduardo Cifuentes Muñoz. Sentencia T-098 de 1994, Corte Constitucional de Colombia, M. P. Eduardo Cifuentes Muñoz.

43 Artículo 3, Ley 1482 de 2011, Congreso de la República de Colombia.

${ }^{44}$ Artículo 4, Ley 1482 de 2011, Congreso de la República de Colombia.

${ }^{45}$ Cfr. Bernal, C., "El juicio de la igualdad en la jurisprudencia de la Corte Constitucional Colombiana", en http://bibliohistorico.juridicas.unam.mx/libros/1/344/5.pdf, p. 55, consultado ocho de agosto de 2016. 
proporcionalidad entre trato y fin perseguido ${ }^{46}$. El segundo test es de origen norteamericano y consta de tres tipos de escrutinios de igualdad de distinta intensidad (estrictos, intermedios y débiles); el escrutinio de igualdad débil busca determinar si la medida es "potencialmente adecuada para alcanzar un propósito que no esté prohibido por el ordenamiento jurídico" 47 ; el escrutinio de igualdad estricto intenta establecer si el trato diferenciado persigue un objetivo constitucionalmente imperioso, y si este es necesario e indispensable para alcanzarlo ${ }^{48}$; el escrutinio de igualdad intermedio pretende ser una categoría entre el escrutinio estricto y el débil, este en particular busca determinar si el trato diferenciado "está ligado de manera sustantiva con la obtención de una finalidad constitucionalmente importante" ${ }^{49}$. Por último, el denominado juicio integrado de proporcionalidad combina las ventajas de los esquemas anteriores, tanto del europeo como del norteamericano ${ }^{50}$. En el juicio integrado de proporcionalidad se intentan introducir los grados de intensidad del test de igualdad norteamericano en el test de índole europea -estructurado alrededor del principio de proporcionalidad- de manera que se aplica una escala diferente de intensidades dentro del principio de proporcionalidad ${ }^{51}$, permitiendo establecer no solo que el trato diferente es necesario e indispensable para alcanzar el fin propuesto, sino que es idóneo y adecuado, por tanto, no hay alternativa posible que represente mayor beneficio frente al sacrificio de derechos.

La Corte Constitucional ha ido aplicando de manera progresiva los distintos esquemas de juicios de igualdad a lo largo del tiempo. En una primera etapa fue más recurrente la aplicación del test de igualdad norteamericano, en especial del escrutinio de igualdad estricto. La Corte ha enumerado los casos en que se hace exigible la aplicación del escrutinio de igualdad estricto para determinar la constitucionalidad de una disposición legal:

El escrutinio judicial debe ser más intenso al menos en los siguientes casos: de un lado, cuando la ley limita el goce de un derecho constitucional a un determinado grupo de personas, puesto que la Carta indica que todas las personas tienen derecho a una igual protección de sus derechos y libertades (CP art. 13). De otro lado, cuando el Congreso utiliza como elemento de diferenciación un criterio prohibido o sospechoso, como la raza, pues la Constitución y los tratados de derechos humanos excluyen el uso de esas categorías (CP art. 13). En tercer término, cuando la Carta señala mandatos específicos de igualdad, como sucede con la equiparación entre todas las confesiones religiosas (CP art, 19), pues en esos eventos, la libertad de configuración del Legislador se ve menguada. Y, finalmente, cuando la regulación

${ }^{46}$ Cfr. Bernal, C., "El juicio de la igualdad en la jurisprudencia de la Corte Constitucional Colombiana", en http://bibliohistorico.juridicas.unam.mx/libros/1/344/5.pdf, p. 57, consultado ocho de agosto de 2016.

${ }^{47}$ Sentencia C-093 de 2001, Corte Constitucional de Colombia, M. P. Alejandro Martínez Caballero.

${ }^{48}$ Cfr. Bernal, C., Ibid., p. 64, consultado ocho de agosto de 2016.

${ }^{49}$ Sentencia C-445 de 1995, Corte Constitucional de Colombia, M. P. Alejandro Martínez Caballero.

${ }^{50}$ Cfr. Op. cit., p. 58.

${ }^{51}$ Cfr. Op. cit., p. 66. 
afecta a poblaciones que se encuentran en situaciones de debilidad manifiesta ya que estas ameritan una especial protección del Estado (CP art. 13) $)^{52}$.

En la experiencia de la Corte, concretamente el trato diferenciado basado en la orientación sexual de las personas debe estudiarse bajo el escrutinio de igualdad estricto, en razón a que la orientación sexual constituye una categoría sospechosa prohibida por la Constitución ${ }^{53}$. Dice expresamente la Corte:

[...] tres razones justifican un control judicial estricto de todo trato diferente de las autoridades contra un homosexual, a saber, (i) que estamos en presencia de grupos minoritarios tradicionalmente discriminados; (ii) que si la orientación sexual se encuentra biológicamente determinada, entonces la diversidad de trato se funda en una categoría prohibida pues equivale a una discriminación por razón de sexo; y (iii) finalmente, que si la preferencia sexual es libremente escogida, entonces se estaría limitando a un grupo de personas - los homosexuales- el libre desarrollo de la personalidad, mientras que a los heterosexuales se les asegura el pleno goce de ese derecho en materia sexual ${ }^{54}$.

En la sentencia de unificación 214 de 2016, la Corte Constitucional dijo aplicar el juicio integrado de proporcionalidad. Así, para determinar el posible trato diferente basado en la categoría sospechosa de la orientación sexual muy seguramente aplicó el mismo escrutinio de igualdad estricto que aplicó en la sentencia C-577 de 2011, y para determinar si el trato diferente entre parejas heterosexuales y las del mismo sexo perseguía una finalidad constitucionalmente admisible, sin duda aplicó el test de proporcionalidad.

Con todo, es posible preguntar si en la aplicación del test de igualdad ¿la Corte Constitucional realmente determinó el grado de afectación del principio de igualdad frente a las diferenciaciones introducidas por los poderes públicos, tratándose de derechos para parejas del mismo sexo respecto de las parejas heterosexuales? Responder a esa pregunta nos ayudará a responder también la pregunta acerca del alcance de la interpretación de la Corte Constitucional frente al ámbito de configuración legislativa del Congreso de la República.

\section{Principio de libre CONFIgURACión legislativa}

Luigi Ferrajoli, autor italiano, figura representativa del garantismo jurídico, afirma que en la lógica del diseño estructural de las constituciones rígidas es inevitable la aparición de antinomias y de lagunas normativas. En ambos casos se concreta una violación,

\footnotetext{
52 Sentencia C-093 de 2001, Corte Constitucional de Colombia, M.P. Alejandro Martínez Caballero.

${ }^{53}$ Cfr. Sentencia T-248 de 2012, Corte Constitucional de Colombia, M. P. Jorge Pretelt Chaljub.

${ }^{54}$ Sentencia C-481 de 1998, Corte Constitucional de Colombia, M.P. Carlos Gaviria Díaz.
} 
bien sea por acción o por omisión, del contenido de la norma constitucional. Mientras que para remediar las antinomias se requiere de una intervención judicial encaminada a abrogar o anular la norma inválida, para eliminar las lagunas normativas se requiere de la intervención legislativa, que tiene por fin la introducción de la norma ausente. Y, precisa Ferrajoli, al respecto: "La solución de tales lagunas no es nunca posible por vía interpretativa, sino que requiere una intervención operativa: precisamente, la del legislador, con la cual se introduce la norma garantista ausente y que constituye, incluso, una intervención debida" 55 .

La Corte Constitucional, como órgano del Estado, y respetuosa del principio democrático y del principio de separación de poderes, reconoce la libertad de configuración legislativa y la prerrogativa que esta le otorga al órgano legislativo, como máximo representante de la voluntad popular, para regular ciertas materias. La Corte ha definido este principio de libre configuración legislativa de la siguiente manera:

La fuerza normativa del principio democrático y del principio de separación de poderes (CP art. 1, 3 y 113) tienen como consecuencia obvia que los otros órganos del Estado, y entre ellos, el juez constitucional, deben respetar la libertad de configuración del Congreso. Ahora bien, si el legislador tiene mayor discrecionalidad en ciertas materias, eso significa que en esos temas las posibilidades de injerencia del juez constitucional son menores; y por ende la intensidad de su control se ve limitada ${ }^{56}$.

Como lo explica Ferrajoli, pueden presentarse lagunas normativas en el ordenamiento jurídico que se constatan por la falta de garantías correlativas a un derecho. En ese caso, corresponde al legislativo eliminar el déficit señalado ${ }^{57}$. Pero en el supuesto que el legislativo no elimine dicho déficit, ¿queda autorizado el órgano judicial para intervenir y corregir este déficit de protección? Si es en cumplimiento del mandato de defensa de la integridad y supremacía de la Constitución Política, se diría que $\sin ^{58}$.

Frente al problema planteado, la Corte ha dispuesto los criterios a continuación:

${ }^{55}$ Ferrajoli, L., Los fundamentos de los derechos fundamentales, Trotta, Madrid, 2001, pp. 188-189. "En ausencia de leyes, excluir la posibilidad de esa integración judicial del ordenamiento tendría como consecuencia el vaciamiento de derechos reconocidos en la Constitución”. Zagrebelsky, G., El derecho dúctil. Ley, derechos, justicia, Editorial Trotta, Madrid, 2011, p. 153.

${ }^{56}$ Sentencia C-093 de 2001, Corte Constitucional de Colombia, M.P. Alejandro Martínez Caballero.

57 Cfr. Ferrajoli, L., Los fundamentos de los derechos fundamentales, Trotta, Madrid, 2001.

58 "Desde esa perspectiva, las lagunas pueden ser superadas por el intérprete autorizado de la Constitución mediante su jurisprudencia (...) la intervención del juez constitucional, como intérprete auténtico, no se hace más que para proteger la supremacía normativa y, con ello, se confiere eficacia a los derechos fundamentales". Pazos, R., El control de la omisión de desarrollo legislativo frente a los derechos sociales: El caso colombiano, Tesis doctoral, Instituto de Derechos Humanos Bartolomé de las Casas, Getafe, 2016, p. 410. 
La cuestión de determinar el tipo o el grado de protección que requieren grupos de personas comparables ha sido confiada al legislador democráticamente elegido. Por eso, al analizar si un grupo de personas está menos protegido que otro, no le corresponde al juez constitucional sustituir la apreciación del legislador ni imponer niveles de protección máximos o ideales. No obstante, sí le compete determinar (i) si el legislador no ha respetado los mínimos de protección constitucionalmente ordenados, (ii) si la desprotección de un grupo excede los márgenes constitucionalmente admisibles, o (iii) si la menor protección relativa de un grupo obedecen a una discriminación, lo cual estaría constitucionalmente prohibido ${ }^{59}$.

El legislador no está por encima de la Constitución, y en la función de crear las leyes está sujeto al marco prescrito por la Constitución. Por un lado, no se concibe que el legislador proteja los derechos fundamentales de un grupo y, por otro, que limite sin más la protección debida a otro grupo, o asigne una carga mayor a este grupo respecto de la asignada al otro, pues contraría el principio de igualdad consagrado en la Constitución (art. $13 \mathrm{CP}$ ). Aun cuando la Constitución no prohíba categóricamente el trato diferencial, incluso lo autorice cuando este se emplea con fines constitucionales, el trato diferencial basado en categorías sospechosas, así como la orientación sexual, está explícitamente prohibido por la Constitución, por lo que se hace necesario el control constitucional abstracto de la Corte Constitucional, a partir de la norma y sus antecedentes, para establecer la razón para el trato diferenciado. Con certeza, pocas veces se encuentran razones jurídicamente atendibles para justificar un trato diferenciado, por lo que el juez constitucional queda facultado para remover del ordenamiento jurídico las regulaciones que estén limitando al grupo el goce pleno de sus derechos y restablecer con esa medida el orden constitucional ${ }^{60}$.

¿Qué hace exactamente que el tribunal constitucional pueda injerir en el acto del legislador? Por un lado, existen derechos que para poder realizarse imponen al Estado una obligación negativa ${ }^{61}$, esto es, un deber de abstención o de no intervención, estos son

\footnotetext{
59 Sentencia C-507 de 2004, Corte Constitucional de Colombia, M. P. Manuel José Cepeda Espinosa.
}

60 "Se plantea el siguiente problema: ¿pueden las normas hacer un uso benévolo de categorías sospechosas? Y para la Corte la respuesta es negativa, pues precisamente la idea misma de nociones sospechosas, o potencialmente discriminatorias, es que su uso por las autoridades se encuentra en principio prohibido (CP art. 13), por lo cual, las regulaciones fundadas en esos criterios se presumen inconstitucionales. Las autoridades deben entonces, en principio, evitar emplear esas clasificaciones, incluso de manera inocente. Por ende, si una diferencia de trato se funda en una categoría potencialmente discriminatoria, tienen que concurrir claras razones que expliquen su empleo, pues de no existir esas justificaciones especiales, y en virtud de la presunción de inconstitucionalidad, el juez constitucional deberá retirar del ordenamiento esas regulaciones”. Sentencia C-112 de 2000, Corte Constitucional de Colombia, M.P. Alejandro Martínez Caballero.

61 "La obligación es negativa cuando el sujeto pasivo, para cumplir con el objeto de la obligación, debe abstenerse de actuar u omitir alguna conducta que pueda ser contraria al respeto y garantía del compromiso adquirido". Pazos, R., El control de la omisión de desarrollo legislativo frente a los derechos sociales: El caso colombiano, Tesis doctoral, Instituto de Derechos Humanos Bartolomé de las Casas, Getafe, 2016, p. 158. 
los derechos característicamente negativos ${ }^{62}$. Por otro lado, hay derechos que suponen prestaciones e imponen al Estado una obligación positiva ${ }^{63}$ o deber de actuación. Entre estos derechos prestacionales encontramos, sobre todo, aquellos de carácter social, pero también hay otros derechos que requieren la actuación positiva del Estado, como son las libertades cuyo ejercicio debe ser regulado expresamente por el legislador, pero si estos derechos o libertades aún no han sido regulados por el legislador, entonces, simplemente no tienen aplicación. Si el legislador viola el deber de no intromisión en los derechos negativos, la garantía que entra a operar es "de tipo jurisdiccional de eliminación de la ley contraria a la Constitución por parte del tribunal constitucional" 64 , pero si el legislador, en cambio, se abstiene de actuar, estando obligado a legislar, y con esto impide la realización de un derecho social o el ejercicio legítimo de una libertad, entonces "se produce una violación por omisión o se configura omisión legislativa"65.

Si frente a la violación del deber de no intromisión del legislador se estatuye una garantía de tipo jurisdiccional que faculta al tribunal constitucional a ejercer un control abstracto acerca del contenido normativo y eliminar la ley contraria a la Constitución, no pasa lo mismo respecto de los casos de violación por omisión, pues no existe ninguna garantía de tipo jurisdiccional que autorice al tribunal constitucional hacer un control abstracto de constitucionalidad respecto del comportamiento negativo del legislador y que ponga fin a los efectos de la inacción del legislador. La Constitución colombiana no consagra dicha garantía, por consiguiente, el único que puede llenar los vacíos de la norma y corregir esta anomalía es el legislador. Para Leonardo García Jaramillo, "la omisión parcial, la acción insuficiente o la inacción por parte de los organismos del gobierno o del Legislativo respecto del amparo de derechos, legitiman una mayor intervención judicial” ${ }^{66}$. Autores como Andrés Morales Velásquez consideran necesaria la intervención del tribunal constitucional para eliminar los efectos de la inacción del legislador, no obstante, presentan objeciones a este tipo de control abstracto, y ven como una mejor vía la aplicación directa de la Constitución ${ }^{67}$. Entre las principales objeciones que se recogen, es factible mencionar: a) la tensión emergente entre el principio de supremacía de la Constitución y el principio democrático; b) la ausencia de normas expresas en

${ }^{62}$ Morales, A. "Un modelo para el control de las omisiones legislativas, su aplicación en la jurisprudencia constitucional comparada y colombiana”, en Pensamiento jurídico, No 32, septiembre 2011, p. 294.

63 "La obligación es positiva cuando el obligado debe actuar o ejercer una acción positiva para cumplir con el objeto del deber". Pazos, R., El control de la omisión de desarrollo legislativo frente a los derechos sociales: El caso colombiano, Tesis doctoral, Instituto de Derechos Humanos Bartolomé de las Casas, Getafe, 2016, p. 158.

${ }^{64}$ Morales, A. "Un modelo para el control de las omisiones legislativas, su aplicación en la jurisprudencia constitucional comparada y colombiana”, en Pensamiento jurídico, N 32, septiembre 2011, p. 294.

${ }^{65}$ Morales, A. "Un modelo para el control de las omisiones legislativas, su aplicación en la jurisprudencia constitucional comparada y colombiana”, en Pensamiento jurídico, No 32, septiembre 2011, p. 294.

${ }^{66}$ García, L., Constitucionalismo deliberativo. Estudio sobre el ideal deliberativo de la democracia y la dogmática constitucional del procedimiento parlamentario, Instituto de Investigaciones Jurídicas, No 727 , México, D. F., 2015 , p. 268.

${ }^{67}$ Cfr. Morales, A., "Un modelo para el control de las omisiones legislativas, su aplicación en la jurisprudencia constitucional comparada y colombiana”, en Pensamiento jurídico, No 32, septiembre 2011, p. 300. 
los ordenamientos jurídicos que autoricen la realización de un control abstracto sobre las omisiones legislativas; c) la transformación de los tribunales constitucionales en legisladores positivos; d) la invasión a la libertad de configuración legislativa, y d) la vulneración del principio de división de poderes ${ }^{68}$.

La Corte Constitucional ha aplicado el control a omisiones relativas del legislativo, mas no a omisiones absolutas. Acerca de estas últimas se ha declarado impedida para conocer ${ }^{69}$.

Ciertamente existen algunas diferencias entre omisiones absolutas y omisiones relativas, de las que nos ha ilustrado Rodrigo Pazos Guerrero ${ }^{70}$.

Del control de omisiones absolutas del legislativo no vamos a pronunciarnos, ya que plantea otro problema, así que enfocaremos nuestro interés en analizar el control judicial constitucional pertinente a las omisiones relativas del legislador. Pazos ha mostrado las ventajas de la aplicación de este tipo de control $^{71}$.

La Corte advirtió, por primera vez, en la sentencia C-075 de 2007, la necesidad de hacer una intervención forzosa, para corregir el trato discriminatorio que afectaba a las parejas homosexuales y restablecer la igualdad de derechos entre parejas homosexuales y heterosexuales en relación con el acceso al régimen legal de protección patrimonial de las uniones maritales de hecho ${ }^{72}$. Sin embargo, fue en pronunciamientos anteriores que la Corte Constitucional estableció los requisitos de procedibilidad de las acciones

${ }^{68}$ Cfr. Morales, A. Ibid., p. 296.

69 "No toda inactividad legislativa puede someterse al trámite del control constitucional, pues cuando se está ante una omisión legislativa absoluta (...) es claro que el órgano de control carece de competencia para emitir pronunciamiento de fondo, pues la misma comporta una ausencia total e íntegra de normatividad que, en cualquier caso, impide una confrontación material, objetiva y verificable con el texto de la Carta Política". Sentencia C-1043 de 2006, Corte Constitucional de Colombia, M.P. Rodrigo Escobar Gil.

70 “Una omisión absoluta (...) se presenta por la ausencia total de desarrollo normativo impuesto en la ley superior, lo cual significa una renuncia o abstención al ejercicio de su competencia y un incumplimiento claro a un deber de desarrollo legislativo; y segundo, una omisión relativa que se produce por la expedición de una regulación legislativa parcial y deficiente, imperfecta o incompleta, en la que no se contemplan todas las situaciones que deben ser objeto de regulación jurídica, lo cual puede traducirse en la violación, interdicción o exclusión de un beneficio o derecho para un sector específico de personas, ya sea por violación al derecho de igualdad sustancial o al debido proceso, entre otros derechos". Pazos, R., El control de la omisión de desarrollo legislativo frente a los derechos sociales: El caso colombiano, Tesis doctoral, Instituto de Derechos Humanos Bartolomé de las Casas, Getafe, 2016, p. 379.

71 “Al respecto, se han diseñado métodos creativos y efectivos de solución de la insuficiencia normativa a través de la integración normativa, la interpretación conforme a la Constitución o la extensión del alcance normativo a otros supuestos fácticos con fin de superar un tratamiento discriminatorio de un sector de la población, entre otros. Es una respuesta judicial muy importante, cada vez más extendida y consolidada y acorde con la misión de defensa del orden constitucional”. Pazos, R., Ibíd., 561.

72 "En principio cabe señalar que la manera como se pueda brindar protección patrimonial a quienes han decidido conformar una pareja como proyecto de vida permanente y singular, entra en el ámbito de configuración legislativa, porque no hay una fórmula única que resulte obligada conforme a la Constitución para ese efecto y la protección requerida puede obtenerse por distintos caminos. Sin embargo, resalta la Corte que ese ámbito de configuración legislativa se encuentra limitado por la Constitución y por el respeto a los derechos fundamentales de las personas. En ese escenario, para la Corte, la ausencia de protección en el ámbito patrimonial para la pareja homosexual resulta lesiva de la dignidad de la persona humana, es contraria 
constitucionales por omisiones legislativas, permitiendo extender, de manera progresiva, los derechos de las parejas heterosexuales a las parejas homosexuales ${ }^{73}$.

De ahí en adelante, puede constatarse en varios fallos de la Corte Constitucional (empezando por la sentencia C-075 de 2007, seguida por las sentencias C-811 de 2007, C-336 de 2008 y C-029 de 2009) que el medio de control de constitucionalidad sobre omisiones legislativas relativas, consistente en la exclusión de un contenido contrario a la Constitución, ha procedido después de aplicar un test de proporcionalidad y advertir la existencia de una omisión legislativa relativa, y ha terminado en sentencia unificadora contentiva de una fórmula en la que se declara la exequibilidad de las expresiones demandadas bajo el entendido de que las disposiciones que las contienen incluyen en su ámbito de aplicación a las parejas del mismo sexo, superando con esto el déficit de protección existente.

A pesar de los avances tan significativos, en la sentencia C-577 de 2011, la Corte Constitucional tuvo que exhortar al Congreso de la República para que legislara de manera sistemática y organizada en el plazo perentorio de 20 de junio de 2013, con la finalidad de eliminar el déficit de protección que aún afectaba a las parejas conformadas por personas del mismo sexo. En esa oportunidad, la Corte Constitucional moduló el fallo con efectos diferidos, de suerte tal, que si el Congreso no legislaba en el término establecido, las parejas del mismo sexo pudieran acudir ante juez o notario de la República para solemnizar y formalizar su vínculo contractual. La Procuraduría General de la Nación, mediante incidente de nulidad, atacó este pronunciamiento, señalando que la Corte había incurrido en una violación directa de la Constitución Política y al debido proceso $^{74}$.

Posteriormente, la Corte Constitucional, en sentencia SU-214 de 2016, afirmando su autonomía en el ejercicio de la función judicial, advirtió que:

al derecho al libre desarrollo de la personalidad y comporta una forma de discriminación proscrita por la Constitución”. Sentencia C-075 de 2007, Corte Constitucional de Colombia, M.P. Rodrigo Escobar Gil.

73 "(i) que exista una norma sobre la cual se predique necesariamente el cargo; (ii) que la misma excluya de sus consecuencias jurídicas aquellos casos que, por ser asimilables, tenían que estar contenidos en el texto normativo cuestionado, o que el precepto omita incluir un ingrediente o condición que, de acuerdo con la Constitución, resulta esencial para armonizar el texto legal con los mandatos de la Carta; (iii) que el Legislador omitió tal obligación, sin que mediara motivo razonable a pesar de que reguló parcialmente la misma materia; (iv) que la falta de justificación y objetividad genere para los casos excluidos de la regulación legal una desigualdad negativa frente a los que se encuentran amparados por las consecuencias de la norma; y (v) que la omisión sea el resultado del incumplimiento de un deber específico impuesto por el constituyente al legislador”. Sentencia C-240 de 2009, Corte Constitucional de Colombia, M. P. Mauricio González Cuervo; Sentencia C-185 de 2002, Corte Constitucional de Colombia, M. P. Rodrigo Escobar Gil; Sentencia C-543 de 1996, Corte Constitucional de Colombia, M. P. Carlos Gaviria Díaz; Sentencia C-427 de 2000, Corte Constitucional de Colombia, M. P. Vladimiro Naranjo Mesa, y Sentencia C-1154 de 2005 , Corte Constitucional de Colombia, M. P. Manuel José Cepeda Espinosa.

${ }^{74}$ Cfr. Auto 155 de 2013, Corte Constitucional de Colombia, Magistrado sustanciador Gabriel Eduardo Mendoza Martelo. 
Tomando en consideración que el Congreso de la República omitió legislar para poner fin al déficit de protección que aqueja a las parejas del mismo sexo en materia de formalización de su vínculo marital solemne, y con base en lo decidido en Sentencia C-577 de 2011, la Corte reitera que el referido vínculo contractual corresponde a la celebración de un matrimonio civil, en los términos del artículo 113 del Código Civil ${ }^{75}$.

Realmente ¿son acertados los señalamientos contra la Corte Constitucional, que la acusan de sustituir la Constitución y usurpar funciones del Congreso de la República en materias en las que esta corporación goza de amplia configuración legislativa? Hay que advertir que la falta de regulación, protección y garantía a los derechos de un grupo social, así sea por omisión, convierte al ordenamiento jurídico colombiano en perpetuador de la discriminación y la desigualdad social y política ${ }^{76}$.

Por un lado, puede acusarse a la Corte de extralimitar sus funciones legales y constitucionales, pero por otro, un argumento a favor de la Corte es que su intervención sirvió para corregir una situación inconstitucional que colocaba a las parejas del mismo sexo en desventaja frente a las parejas de distinto sexo en el goce efectivo de sus derechos. No se debe olvidar que la Corte Constitucional ya había llamado la atención acerca del déficit de protección jurídica que afectaba a las parejas de personas del mismo sexo y había exhortado al Congreso para que legislara en un término razonable y de manera sistemática y organizada. Exhorto que nunca llegó a su cometido. Hay que decirlo, la inacción del Congreso de la República generaba una carga desproporcionada a las parejas del mismo sexo, que no estaban obligadas a soportar. Así que, para afrontar esta situación inconstitucional, la intervención de la Corte se debe considerar proporcionada para poner fin a las barreras jurídicas que impedían a las parejas del mismo sexo gozar de sus derechos constitucionales, concretamente, de los derechos a contraer matrimonio y a formar una familia. El aspecto principal que se debe atender en estos casos es el alcance normativo que tienen los derechos fundamentales en los tribunales: "los derechos fundamentales adscritos por las constituciones son, con todo, normas positivas dotadas de alcance normativo. Entran a formar parte del lenguaje y de la práctica jurídica desempeñando, sobre todo en la jurisprudencia de los tribunales un papel normativo que depende, obviamente, de su interpretación" 77 . La intervención judicial en el ámbito de configuración legislativa no debe entenderse como una excepción al principio de libre configuración legislativa que asiste al órgano legislativo en su función constitucional. En su lugar, adquieren preeminencia el principio de colaboración armónica y el principio democrático.

\footnotetext{
${ }^{75}$ Sentencia SU-214 de 2016, Corte Constitucional de Colombia, M.P. Alberto Rojas Ríos.

${ }^{76}$ Cfr. Peña, R. \& Parada, M., "Tensión entre la democracia inclusiva y la mayoría: el matrimonio igualitario en el Congreso colombiano", en Revista de Derecho Universidad del Norte, No 42, 2014 , p. 91. Cfr. Quinche, M. \& Peña, R, El derecho judicial de la población LGTBI y de la familia diversa, Legis Editores, Universidad del Rosario, Bogotá, 2013, p. 48.

${ }^{77}$ Ferrajoli, L., Los fundamentos de los derechos fundamentales, Trotta, Madrid, 2001, p. 182.
} 
No se puede desconocer que, por mandato superior, a la Corte Constitucional "se le confía la guarda de la integridad y supremacía de la Constitución” (art. 241 CP), y mal haría si se apartara de estos fines. Si la Corte Constitucional hubiera desatendido el déficit de protección jurídica que ya afectaba a las personas homosexuales habría incurrido en una falta grave a sus funciones, peor aún, hubiera traicionado los ideales de una Constitución que se precia de ser garantista, pluralista, fundada en el respeto a la dignidad humana (art. 1 CP).

Ciertamente la Corte Constitucional en la sentencia SU-214 de 2016 y en la C-577 de 2011 no aplicó con rigurosidad el test de igualdad de conformidad con los derechos constitucionales afectados por el trato diferenciado, de modo que resultara un juicio de proporcionalidad en sus distintas etapas -adecuación, idoneidad y proporcionalidad en sentido estricto- sobre el trato diferenciado. Por ello tampoco hay que calificar su decisión como no ajustada a derecho, incluso en contra del derecho.

La posición garantista de la Corte a favor de los derechos constitucionales de las parejas del mismo sexo parte de la base misma de los principios de la democracia sustancial, que rescatan la dimensión jurídica de la democracia, y cuestionan el poder de las mayorías sobre las decisiones que conciernen a una minoría ${ }^{78}$.

Respecto del lugar que ocupan y el papel que desempeñan las minorías en una democracia, concretamente las personas homosexuales, se ha dicho que "las decisiones que tocan a minorías políticas, como es el caso de la comunidad LGBTI, no pueden ser sometidas a consideración de las mayorías mediante una consulta o referendo, como plantean algunos congresistas y académicos, pues es por esta mayoría que existe una condición vulnerable dentro de la sociedad colombiana para estas personas"79. Así, el papel que pueden llegar a desempeñar los tribunales constitucionales tendiente al control de las omisiones legislativas y al restablecimiento de derechos, sobre todo de las minorías, resulta fundamental para garantizar el sostenimiento de una democracia.

El tribunal constitucional es "el guardián de la Constitución" 80 , eso lo convierte en actor político, de no menos categoría que el legislativo, desempeñando un papel muy importante al interior de una democracia. En ese entendido, la intervención del tribunal constitucional, siempre que sea para corregir el modelo democrático y asegurar

78 “ $[\mathrm{L}]$ os derechos fundamentales, a diferencia de los demás derechos, vienen a configurarse como otros tantos vínculos sustanciales normativamente impuestos -en garantía de intereses y necesidades de todos estipulados como vitales, por eso "fundamentales" (la vida, la libertad, la subsistencia) - tanto a las decisiones de la mayoría como al libre mercado". Ferrajoli, L, Los fundamentos de los derechos fundamentales, Trotta, Madrid, 2001, p. 35.

${ }^{79}$ Peña, R. \& Parada, M., "Tensión entre la democracia inclusiva y la mayoría: el matrimonio igualitario en el Congreso colombiano", en Revista de Derecho Universidad del Norte, No 42, 2014, p. 78. Cfr. Estrada, S., "Familia, matrimonio y adopción: algunas reflexiones en defensa del derecho de las parejas del mismo sexo a constituir familia y de los menores a tenerla", en Revista de Derecho Universidad del Norte, N ${ }^{\circ} 36,2011$, pp. 135-136. Cfr. García, L., “¿Cómo pensar hoy la tensión entre constitucionalismo y democracia? Una perspectiva desde el constitucionalismo democrático, en Revista da Facultade de Direito UFPR, Vol. 60, N 2, mayo 2015, pp. 72-77.

${ }^{80}$ Cfr. Barzotto, L., "El guardián de la Constitución”, en Dikaion Universidad de La Sabana, Vol. 19, $\mathrm{N}^{\circ}$ 2, diciembre 2010, pp. 443-444. 
el derecho, no solo goza de toda legitimidad sino que resulta del todo necesaria en una democracia constitucional.

\section{Conclusiones}

La sentencia C-577 de 2011 fue emblemática y marcó un giro en la jurisprudencia nacional, por cuanto hizo un reconocimiento explícito de las parejas conformadas por personas del mismo sexo como un tipo de familia amparado por el ordenamiento jurídico colombiano, pero también porque identificó un déficit de protección jurídica de estas parejas. En esa sentencia, la Corte Constitucional resolvía la demanda de inconstitucionalidad que pretendía la declaración de constitucionalidad condicionada de la norma que regulaba la institución del matrimonio, consagrada en el artículo 113 del Código Civil. La Corte declaró exequible dicha norma, salvaguardando la institución del matrimonio entre heterosexuales de modo compatible con el artículo 42 de la Constitución Política. Sin embargo, la declaración de exequibilidad del artículo 113 del Código Civil no obstaba para que el legislador definiera los caracteres y alcances de una institución que, brindándole a las parejas homosexuales la alternativa de formalizar su unión, tornara posible superar el déficit de protección. En ese sentido, el fallo hizo expreso un exhorto de la Corte Constitucional al Congreso de la República para que, en el plazo perentorio de 20 de junio de 2013, legislara de manera sistemática y organizada con la finalidad de eliminar el déficit de protección que afectaba a las parejas conformadas por personas del mismo sexo.

El amparo que en anteriores ocasiones la Corte ha prohijado a los derechos de las personas homosexuales en su dimensión individual, basado en el derecho a la igualdad, a la dignidad humana y al libre desarrollo de la personalidad, ahora se extiende a derechos, como a conformar una familia y a contraer matrimonio.

La declaración del derecho constitucional de las parejas del mismo sexo a unirse para constituir un vínculo marital en Colombia conduce no solamente a la celebración del matrimonio civil entre parejas del mismo sexo, entre otros resultados, también a la constitución formal de una familia; el surgimiento de los deberes de fidelidad y mutuo socorro; la modificación del estado civil de los contratantes; el surgimiento de la sociedad conyugal; el ingreso de los contratantes en el respectivo orden sucesoral; la posibilidad de suscripción de capitulaciones; la claridad en las causales de terminación del vínculo entre los contratantes; llegar a establecer su residencia en otros países, e invocar ciertos beneficios en materia tributaria por tener cónyuge o compañero permanente.

A pesar de que la Corte Constitucional encontró que el trato diferente de las parejas heterosexuales y las del mismo sexo, introducido por el legislador en el artículo 113 del Código Civil al emplear la expresión "un hombre y una mujer”, no cumplía un fin constitucionalmente válido, al estar consagrada la misma expresión en la Constitución Política, no podía la Corte Constitucional ejercer un control estricto de constitucionalidad sobre el artículo 113 del Código Civil ni el artículo 42 de la Constitución, pues habría incurrido en sustitución de la Constitución, y para ello debía haberse adelantado 
un acto reformatorio de la Constitución que ya no era competencia de la Corte. El test de igualdad no tuvo el alcance esperado, pero sí la declaración de omisión relativa del legislativo para superar el déficit de protección a las parejas del mismo sexo en materia de formalización y solemnización de su vínculo contractual, déficit que sí está prohibido constitucionalmente.

Cuando se presenta un déficit de protección debe el legislativo implementar las medidas necesarias para eliminarlo, con el agravante de que si no lo hace se perpetúa dicho déficit bajo forma de discriminación, haciéndose imperiosa la intervención judicial para poder corregir este déficit de protección en defensa de la integridad y supremacía de la Constitución Política. La intervención judicial procede por vía de control constitucional abstracto de la ley. Esta intervención no comporta necesariamente una excepción al principio de libre configuración legislativa, sino que más bien se justifica por el principio de colaboración armónica y el principio democrático. Queda demostrada la hipótesis respecto de la competencia del tribunal constitucional para intervenir en caso de omisión relativa del órgano legislativo y poner fin a un déficit de protección jurídica manifiesto.

\section{BIBLIOGRAFÍA}

Barzotto, L., "El guardián de la Constitución”, en Dikaion Universidad de La Sabana, Vol. 19, $\mathrm{N}^{\circ}$ 2, diciembre 2010.

Bernal, C., "El juicio de la igualdad en la jurisprudencia de la Corte Constitucional Colombiana", en http://bibliohistorico.juridicas.unam.mx/libros/1/344/5.pdf, consultado ocho de agosto de 2016.

Estrada, S., "Familia, matrimonio y adopción: algunas reflexiones en defensa del derecho de las parejas del mismo sexo a constituir familia y de los menores a tenerla", en Revista de Derecho Universidad del Norte, $\mathrm{N}^{\circ}$ 36, 2011.

Ferrajoli, L., Los fundamentos de los derechos fundamentales, Trotta, Madrid, 2001.

García, L., Constitucionalismo deliberativo. Estudio sobre el ideal deliberativo de la democracia y la dogmática constitucional del procedimiento parlamentario, Instituto de Investigaciones Jurídicas, $\mathrm{N}^{\mathrm{o}} 727$, México, D. F., 2015.

García, L., “¿Cómo pensar hoy la tensión entre constitucionalismo y democracia? Una perspectiva desde el constitucionalismo democrático, en Revista da Facultade de Direito UFPR, Vol. 60, $\mathrm{N}^{\circ}$ 2, mayo 2015.

Morales, A., "Un modelo para el control de las omisiones legislativas, su aplicación en la jurisprudencia constitucional comparada y colombiana", en Pensamiento jurídico, $\mathrm{N}^{\circ} 32$, septiembre 2011.

PÁEZ, M., "La sentencia C-577 de 2011 y el matrimonio igualitario en Colombia", en Revista Derecho del Estado Universidad Externado de Colombia, No 31, julio 2013.

Pazos, R., El control de la omisión de desarrollo legislativo frente a los derechos sociales: El caso colombiano, Tesis doctoral, Instituto de Derechos Humanos Bartolomé de las Casas, Getafe, 2016.

PeÑA, R. \& Parada, M., "Tensión entre la democracia inclusiva y la mayoría: el matrimonio igualitario en el Congreso colombiano", en Revista de Derecho Universidad del Norte, $\mathrm{N}^{\circ} 42$, 2014. 
Quinche, M. \& Peña, R., El derecho judicial de la población LGTBI y de la familia diversa, Legis Editores, Universidad del Rosario, Bogotá, 2013.

VÁsquez, S., La Argumentación Judicial, Librería Jurídica Sánchez Ltda., Medellín, 2003.

Zagrebelsky, G., El derecho dúctil. Ley, derechos, justicia, Editorial Trotta, Madrid, 2011.

\section{Legislación y jurisprudencia}

Auto 155 de 2013, Corte Constitucional de Colombia, Magistrado sustanciador Gabriel Eduardo Mendoza Martelo.

Código Civil Colombiano, Congreso de la República de Colombia, 1887.

Código General del Proceso, Congreso de la República de Colombia, 2012.

Constitución Política de Colombia, Asamblea Nacional Constituyente de Colombia, 1991.

Convención Americana sobre Derechos Humanos 'Pacto de San José de Costa Rica', Organización de Estados Americanos, 1969.

LEY 1482, Congreso de la República de Colombia, 2011.

Pacto Internacional de Derechos Civiles y Políticos, Asamblea General de las Naciones Unidas, 1966.

Principios de Yogyakarta, Consejo de Derechos Humanos de las Naciones Unidas, 2007.

Sentencia T-097 de 1994, Corte Constitucional de Colombia, M.P. Eduardo Cifuentes Muñoz. Sentencia T-098 de 1994, Corte Constitucional de Colombia, M. P. Eduardo Cifuentes Muñoz. Sentencia T-539 de 1994, Corte Constitucional de Colombia, M. P. Vladimiro Naranjo Mesa. Sentencia C-445 de 1995, Corte Constitucional de Colombia, M. P. Alejandro Martínez Caballero. Sentencia C-543 de 1996, Corte Constitucional de Colombia, M. P. Carlos Gaviria Díaz. Sentencia C-481 de 1998, Corte Constitucional de Colombia, M. P. Carlos Gaviria Díaz. Sentencia C-112 de 2000, Corte Constitucional de Colombia, M. P. Alejandro Martínez Caballero. Sentencia C-371 de 2000, Corte Constitucional de Colombia, M. P. Carlos Gaviria Díaz. Sentencia C-427 de 2000, Corte Constitucional de Colombia, M. P. Vladimiro Naranjo Mesa. Sentencia C-093 de 2001, Corte Constitucional de Colombia, M. P. Alejandro Martínez Caballero. Sentencia C-185 de 2002, Corte Constitucional de Colombia, M. P. Rodrigo Escobar Gil. Sentencia T-301 de 2004, Corte Constitucional de Colombia, M. P. Eduardo Montealegre Lynett. Sentencia C-507 de 2004, Corte Constitucional de Colombia, M. P. Manuel José Cepeda Espinosa. Sentencia C-1154 de 2005, Corte Constitucional de Colombia, M. P. Manuel José Cepeda Espinosa.

Sentencia C-1043 de 2006, Corte Constitucional de Colombia, M.P. Rodrigo Escobar Gil. Sentencia C-075 de 2007, Corte Constitucional de Colombia, M.P. Rodrigo Escobar Gil. Sentencia C-811 de 2007, Corte Constitucional de Colombia, M.P. Marco Gerardo Monroy Cabra. Sentencia C-336 de 2008, Corte Constitucional de Colombia, M. P. Clara Inés Vargas Hernández. Sentencia C-029 de 2009, Corte Constitucional de Colombia, M. P. Rodrigo Escobar Gil. Sentencia C-240 de 2009, Corte Constitucional de Colombia, M. P. Mauricio González Cuervo. Sentencia C-577 de 2011, Corte Constitucional de Colombia, M. P. Gabriel Eduardo Mendoza Martelo.

Sentencia T-248 de 2012, Corte Constitucional de Colombia, M. P. Jorge Pretelt Chaljub. Sentencia SU-214 de 2016, Corte Constitucional de Colombia, M. P. Alberto Rojas Ríos. 
